\title{
Detecção do gene da nucleoproteína do vírus da cinomose canina por RT-PCR em urina de cães com sinais clínicos de cinomose
}

[Detection of canine distemper virus nucleoprotein gene by RT-PCR in urine of dogs with distemper clinical signs]

\author{
C.M.S. Gebara ${ }^{1}$, S.R. Wosiacki ${ }^{1}$, F.J. Negrão ${ }^{1}$, D.B de Oliveira ${ }^{1}$, \\ S.N.E. Beloni ${ }^{2}$, A.A. Alfieri $^{3 *}$, A.F. Alfieri $^{3}$ \\ ${ }^{1}$ Programa de Pós-graduação em Ciência Animal - UEL \\ ${ }^{2}$ Departamento de Clínicas Veterinárias - Centro de Ciências Agrárias - UEL \\ ${ }^{3}$ Laboratório de Virologia Animal - Departamento de Medicina Veterinária Preventiva - UEL \\ Caixa Postal 6001 \\ 86051-990 - Londrina, PR
}

\begin{abstract}
RESUMO
A presença do vírus da cinomose canina (CDV) foi avaliada pela reação em cadeia da polimerase, precedida de transcrição reversa (RT-PCR), em 87 amostras de urina de cães que apresentavam sinais clínicos sugestivos de cinomose. Os animais foram distribuídos em três grupos. No grupo A foram incluídos 41 cães com alterações sistêmicas; no grupo B, 37 cães com alterações neurológicas; e no grupo C, nove cães com alterações sistêmicas e neurológicas simultâneas. O grupo D (controle) foi composto por 20 cães assintomáticos. Os resultados da RT-PCR foram correlacionados com a forma clínica da infecção e com as alterações hematológicas encontradas. Foi possível a amplificação parcial do gene da nucleoproteína do CDV em 41 (47,1\%) das 87 amostras de urina provenientes de cães com sinais clínicos sugestivos de cinomose. Todas as amostras obtidas de animais assintomáticos foram negativas na RTPCR. Amostras positivas foram encontradas nos três grupos de animais com sinais clínicos na proporção de $51,2 \%(24 / 41), 29 \%(11 / 37)$ e $100 \%$ (9/9) para os grupos A, B e C, respectivamente. A leucocitose foi a alteração hematológica mais freqüente nos três grupos de cães com sinais clínicos porém, não foi possível estabelecer correlação entre o resultado da RT-PCR e as alterações hematológicas. Os resultados demonstraram que, independente da forma de apresentação clínica, a técnica da RT-PCR realizada em urina pode ser utilizada no diagnóstico ante mortem da infecção pelo CDV.
\end{abstract}

Palavras-chave: cinomose canina, vírus da cinomose, urina, RT-PCR

\begin{abstract}
The urine of 87 dogs with clinical signs suggestive of canine distemper was analyzed by RT-PCR for detection of canine distemper virus (CDV) nucleoprotein gene. The samples were allotted to the following groups: group A- with 41 dogs with systemic symptoms, group B- with 37 dogs with neurological signs, and group $C$ - with 9 dogs with simultaneous systemic and neurological clinical signs. Group D (control) included 20 assymptomatic dogs. A $\chi^{2}$ was used to test RT-PCR results according to clinical form and hematological characteristics. The RT-PCR was positive for CDV in 47\% (41/87) of the urine samples from dogs with clinical signs. All samples from assymptomatic dogs were RT-PCR negatives. Positive samples were found in all groups of dogs with distemper symptoms according to the following propositions: $51.2 \%(21 / 41), 29 \%(11 / 37)$ and $100 \%(9 / 9)$ for groups $A, B$ and $C$, respectively. In all clinical forms (groups $A, B$ and $C$ ) leucocytosis was the most frequent observed hematological alteration.
\end{abstract}

Apoio Financeiro: CNPq, CAPES, CPG/UEL

Recebido para publicação em 28 de abril de 2003.

Recebido para publicação, após modificações, em 12 de fevereiro de 2004.

*Autor para correspondência.

E-mail: alfieri@uel.br 
No relationship between RT-PCR results and hematological changes was observed. The results showed that independently of the clinical stage of the illness the RT-PCR based on urine sample can be applied for ante mortem diagnosis of $C D V$.

Keywords: canine distemper, canine distemper virus, urine, $R T-P C R$

\section{INTRODUÇÃO}

$\mathrm{O}$ vírus da cinomose canina (canine distemper vírus-CDV), classificado no gênero Morbillivirus da família Paramixoviridae (Van Regenmortel et al., 2000), é um vírus RNA fita simples de polaridade negativa, considerado um dos mais importantes patógenos de cães jovens $\mathrm{e}$ adultos em todo mundo (Appel e Summers, 1995; Frisk et al. 1999).

Os sinais clínicos da cinomose canina podem variar de acordo com a virulência da estirpe viral infectante, com o estado imunológico e com a idade dos cães. Com maior freqüência são observadas alterações oculares, respiratórias, gastrointestinais e neurológicas. Esses sinais podem, isoladamente ou em associação, ser encontrados em outras doenças infecciosas, dificultando o diagnóstico clínico (Rude, 1987; Shell, 1990; Tipold, 1995).

Exames complementares como hemograma, análise do líquor, exame radiográfico e métodos sorológicos também não possibilitam a realização do diagnóstico diferencial conclusivo da infecção pelo CDV em cães (Appel e Summers, 1999; Moritiz et al., 2000). A pesquisa de corpúsculos de inclusão do CDV, em células de secreções e em neutrófilos circulantes, é considerada uma forma de diagnóstico conclusiva, porém constitui uma alteração pouco freqüente. Nos casos negativos o diagnóstico torna-se inconclusivo, impossibilitando a exclusão do $\mathrm{CDV}$ como causa primária dos sinais clínicos (Motohashi et al., 1969; Jones et al., 2000).

Como as lesões induzidas pelo CDV no sistema nervoso central (SNC) são bastante características, a histopatologia é uma técnica que pode ser utilizada como diagnóstico definitivo dessa virose. Este procedimento constitui um diagnóstico post mortem, não permitindo o diagnóstico precoce e ante mortem da infecção (Carlton e McGavin, 1998; Jones et al., 2000).
Os métodos que empregam a biologia molecular, e em particular a reação em cadeia da polimerase (PCR), têm contribuído com o diagnóstico etiológico de diversas viroses em animais. As principais vantagens dessa técnica, precedida por uma etapa de transcrição reversa (RT-PCR), para os vírus RNA incluem a rapidez na obtenção dos resultados, a não exigência da infecciosidade da partícula viral e os altos níveis de sensibilidade e especificidade. A RT-PCR tem sido empregada com sucesso na deteç̧ão do CDV em diferentes tipos de amostras biológicas como sangue, soro, urina e fragmentos de órgãos (Shin et al., 1995; Frisk et al., 1999; Saito, 2001; Gebara et al., 2004).

O presente trabalho teve como objetivo utilizar a técnica da RT-PCR para a detecção do CDV em urina de cães com sinais clínicos sugestivos de cinomose e correlacionar os resultados com a evolução clínica e alterações hematológicas.

\section{MATERIAL E MÉTODOS}

A estirpe Rockborn do CDV, amplificada em células MDCK (Madin Darby canine kidney) mantidas em meio mínimo essencial Eagle's ${ }^{1}$, foi utilizada como controle positivo na técnica da RT-PCR.

No período de janeiro a dezembro de 2001 foram colhidas 87 amostras de urina de cães com sinais clínicos sugestivos de cinomose e 20 amostras colhidas de cães assintomáticos atendidos no Hospital Veterinário da Universidade Estadual de Londrina e em clínicas veterinárias do município de Maringá, região Norte do Estado do Paraná. A evolução clínica dos animais foi acompanhada por 15 dias. Os cães foram distribuídos em quatro grupos constituídos por: i) grupo A- 41 cães com alterações clínicas sistêmicas; ii) grupo B- 37 cães com alterações clínicas neurológicas; iii) grupo C- nove cães que apresentaram simultaneamente alterações

${ }^{1}$ Invitrogen ${ }^{\mathrm{TM}}$ Life Technology, Carlsbad, USA 
clínicas sistêmicas e neurológicas; e iv) grupo D20 cães assintomáticos que constituíram o grupocontrole.

As amostras de urina, colhidas por micção espontânea em frasco estéril ou por meio de sonda uretral em seringa plástica estéril, foram processadas imediatamente após a colheita ou armazenadas a $4^{\circ} \mathrm{C}$ por no máximo $48 \mathrm{~h}$. Para a realização do hemograma foi colhida uma alíquota de aproximadamente $5 \mathrm{ml}$ de sangue com anticoagulante (EDTA 10\%), em frasco estéril. Os exames foram realizados em analisador hematológico automático ${ }^{2}$. O hemograma foi interpretado de acordo com os parâmetros descritos por Feldman et al. (2000).

A extração do RNA do CDV foi realizada a partir de uma alíquota de $300 \mu 1$ de urina de acordo com o método da sílica / tiocianato de guanidina descrito por Boom et al. (1990). O ácido nucléico foi eluído a $56^{\circ} \mathrm{C} / 15 \mathrm{~min}$ em $40 \mu \mathrm{l}$ de água ultrapura autoclavada, tratada com $1 \mu \mathrm{l}$ (26 unidades/ $\mu \mathrm{l}$ ) de inibidor de RNAse ${ }^{3}$. Como controle negativo, alíquotas de água ultrapura autoclavada foram incluídas em todas as extrações.

Para a realização da RT-PCR foram utilizados os oligonucleotídeos iniciadores CDV1 (+) [5'-aca gga ttg ctg agg acc tat-3', nt 769-789] e CDV2 () [5'-caa gat aac cat gta cgg tgc-3', nt.10551035] (Frisk et al., 1999), que amplificam um produto de 287 pares de bases (pb) do gene que codifica a nucleoproteína do CDV.

A transcrição reversa foi realizada com $9 \mu 1$ de RNA e 20pmol do iniciador CDV1 que foram desnaturados a $70^{\circ} \mathrm{C}$ por $10 \mathrm{~min}$ e imediatamente transferidos para banho de gelo por $5 \mathrm{~min}$. Posteriormente, foi adicionada a solução RTMIX constituída de $0,2 \mathrm{mM}$ de cada $\mathrm{dNTP}^{1}, 1 \mathrm{x}$ tampão-PCR (20mM Tris- $\mathrm{HCl}$ pH 8,4 e $50 \mathrm{mM}$ $\mathrm{KCl}), 1,5 \mathrm{mM} \mathrm{MgCl}_{2}, 100$ unidades da enzima M-MLV reverse transcriptase ${ }^{1}$ e água ultrapura autoclavada para o volume final de $20 \mu \mathrm{l}$. Após homogeneização, a solução foi incubada a $42^{\circ} \mathrm{C}$ por $30 \mathrm{~min}$, seguida da inativação da enzima a $70^{\circ} \mathrm{C}$ por $10 \mathrm{~min}$.

${ }^{2}$ MS4 - MELet SCHLOESING Laboratories, Troisdorf, GE ${ }^{3}$ RNAguard-Pharmacia Biotech ${ }^{\circledR}$, Piscataway, EUA
Para a reação da PCR foram utilizados $5 \mu \mathrm{l}$ do cDNA, 20pmol de cada um dos iniciadores (CDV1 e CDV2), 0,2mM de cada dNTP, 1x tampão-PCR (20mM Tris-HCl pH 8,4 e $50 \mathrm{mM}$ $\mathrm{KCl}$ ), $1,5 \mathrm{mM}$ de $\mathrm{MgCl}_{2}$, 2,5unidades de Taq DNA polymerase, recombinant ${ }^{1}$ e água ultrapura autoclavada para o volume final de $50 \mu \mathrm{l}$. A reação foi realizada em termociclador ${ }^{4}$, utilizando as seguintes condições de tempo e temperatura: i) uma etapa de desnaturação inicial a $94^{\circ} \mathrm{C}$ por $1 \mathrm{~min}$; ii) 40 ciclos de $94^{\circ} \mathrm{C}$ por $1 \mathrm{~min}$, $59^{\circ} \mathrm{C}$ por $2 \mathrm{~min}$ e $72^{\circ} \mathrm{C}$ por $1 \mathrm{~min}$; iii) uma etapa de extensão final a $72^{\circ} \mathrm{C}$ por $7 \mathrm{~min}$. Todas as reações foram realizadas na presença de controles negativos da extração do ácido nucleico e do sistema de PCR, representados por urina de cães assintomáticos e água ultrapura autoclavada.

Os produtos amplificados pela RT-PCR foram analisados por eletroforese em gel de agarose a 2\% em tampão TBE pH 8,4 (Tris 89mM, ácido bórico $89 \mathrm{mM}$, EDTA $2 \mathrm{mM}$ ), sob voltagem constante $(90 \mathrm{~V})$ por aproximadamente $45 \mathrm{~min}$. O gel foi corado em solução contendo $0,5 \mu \mathrm{g} / \mathrm{ml}$ de brometo de etídeo e visualizado sob luz ultravioleta.

A especificidade dos produtos amplificados na RT-PCR foi avaliada pela análise do perfil de restrição com a enzima Hinf I (10 unidades/ $\mu \mathrm{l}){ }^{1}$, selecionada por meio da análise da seqüência do CDV (GenBank: ${ }^{\circ}$ de acesso NC 001921) pelo software Gene Runner (disponível em http://www.generunner.com). A clivagem dos amplicons foi realizada de acordo com as recomendações do fabricante. Os fragmentos obtidos foram também analisados por eletroforese em gel de agarose como descrito anteriormente.

Para avaliar as diferenças entre as proporções de amostras positivas e negativas para o CDV entre os grupos de cães que manifestaram as formas clínicas sistêmica e neurológica e a associação entre formas sistêmica e neurológica, utilizou-se o teste do qui-quadrado $\left(\chi^{2}\right)$ com nível de significância de 5\%. Para a realização dos cálculos estatísticos foi empregado o programa EpiInfo 6,04b (Dean et al., 1997).

${ }^{4}$ MJ Research Co. Water Town, MA, EUA 


\section{RESULTADOS E DISCUSSÃO}

Das 87 amostras de urina (grupos A, B e C), provenientes de cães com sinais clínicos sugestivos de cinomose, a RT-PCR detectou 41 $(47, \%)$ amostras positivas para o CDV (Tab. 1). As $20(100 \%)$ amostras de urina utilizadas como controle (grupo D), obtidas de cães assintomáticos, foram negativas. A Fig. 1 mostra o produto de cDNA amplificado (287pb) a partir de amostra de urina positiva pela RT-PCR e os fragmentos de $60 \mathrm{pb}$ e $227 \mathrm{pb}$ gerados pela clivagem com a endonuclease Hinf I.

Tabela 1. Resultados da técnica da RT-PCR para a detecção do gene da nucleoproteína do vírus da cinomose canina em urina de cães com diferentes formas clínicas da infecção

\begin{tabular}{lcccc}
\hline \multirow{2}{*}{ Grupo } & \multirow{2}{*}{ Forma clínica } & \multirow{2}{*}{ Amostra analisada } & \multicolumn{2}{c}{ RT-PCR } \\
\cline { 3 - 5 } & & & Positiva (\%) & Negativa (\%) \\
\hline A & Sistêmica & 41 & $21(51,2) \mathrm{A}$ & $20(48,8)$ \\
$\mathrm{B}$ & Neurológica & 37 & $11(29,7) \mathrm{A}$ & $26(70,3)$ \\
$\mathrm{C}$ & Sistêmica e neurológica & 9 & $9(100,0) \mathrm{B}$ & - \\
Total & & 87 & $41(47,1)$ & $46(52,9)$ \\
\hline
\end{tabular}

Resultados seguidos por letras distintas na coluna diferem entre si pelo teste do $\chi^{2}(\mathrm{P}<0,05)$.

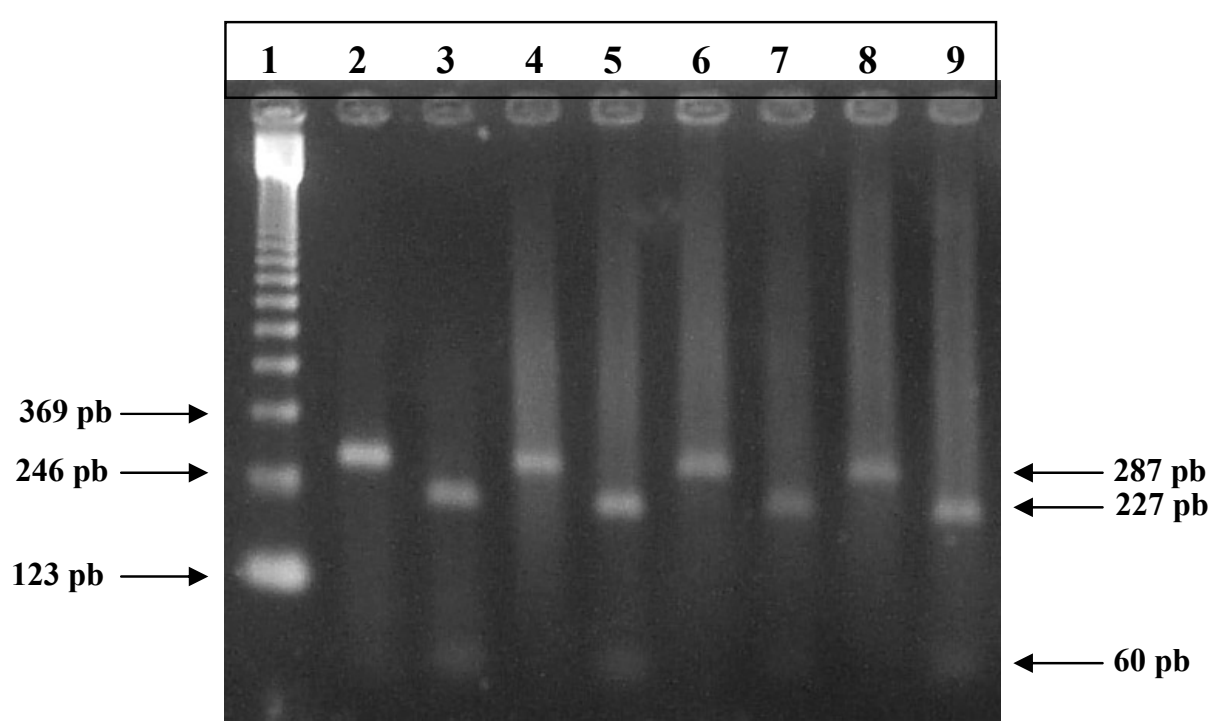

Figura 1. Eletroforese em gel de agarose $2 \%$, corado com brometo de etídio, dos produtos da amplificação parcial do gene da nucleoproteína do vírus da cinomose canina, obtidos pela técnica da RT-PCR realizada em urina de cães com sinais clínicos de cinomose, e dos fragmentos do cDNA clivado com a enzima de restrição Hinf I. Canaleta 1. Padrão de tamanho molecular de 123 pb (Invitrogen ${ }^{\mathrm{TM}}$ Life Technology, EUA); Canaletas 2 e 3. Estirpe Rockborn do vírus da cinomose canina (controle positivo), não clivada (2) e clivada com a enzima Hinf I (3); Canaletas 4, 6 e 8. Amostras de urina de cães com sinais clínicos sugestivos de cinomose canina nas formas sistêmica (4), neurológica (6) e sistêmica/neurológica simultâneas (8); Canaletas 5, 7 e 9. Amostras de urina referentes as canaletas 4, 6 e 8, clivadas com a enzima Hinf I.

A RT-PCR realizada na urina dos cães incluídos no grupo A proporcionou o diagnóstico do CDV em 51\% (21/41) dos animais avaliados. A Tab. 2 apresenta os principais sinais clínicos observados nos cães incluídos nesse grupo. $\mathrm{Na}$ forma sistêmica da infecção pelo CDV os sinais 
clínicos como apatia, anorexia, secreção óculonasal, tosse, vômito e diarréia, apesar de inespecíficos, são considerados freqüentes em cães com cinomose (Rude, 1987; Appel e Summers, 1995). Nessa situação, a confirmação do diagnóstico do CDV possibilita ao clínico a adoção de condutas terapêuticas mais apropriadas e, particularmente nos casos negativos, abre a perspectiva da realização de novas condutas para o esclarecimento do diagnóstico.

Tabela 2. Freqüência dos sinais clínicos encontrados em cães com diagnóstico clínico sugestivo de cinomose, distribuída de acordo com o resultado da RT-PCR para a detecção do gene da nucleoproteína do vírus da cinomose canina, realizada em urina

\begin{tabular}{|c|c|c|c|c|}
\hline \multirow{2}{*}{ Forma clínica } & \multirow{2}{*}{ Sinal clínico } & \multirow{2}{*}{$\begin{array}{c}\text { Amostra } \\
\text { analisada }\end{array}$} & \multicolumn{2}{|c|}{ RT-PCR } \\
\hline & & & Positiva & Negativa \\
\hline \multirow[t]{3}{*}{ Sistêmica } & Gastroenterite, conjuntivite, secreção nasal e tosse & 21 & 11 & 10 \\
\hline & Conjuntivite, secreção nasal e tosse & 8 & 3 & 5 \\
\hline & Gastroenterite & 7 & 4 & 3 \\
\hline \multirow[t]{5}{*}{ Neurológica } & Convulsão, ataxia e mioclonia & 4 & 4 & - \\
\hline & Apatia e anorexia & 5 & 3 & 2 \\
\hline & Convulsão e ataxia & 18 & 3 & 15 \\
\hline & Convulsão & 13 & 3 & 10 \\
\hline & Mioclonia & 2 & 1 & 1 \\
\hline \multirow[t]{2}{*}{ Sistêmica e neurológica } & Convulsão, ataxia, mioclonia, secreção óculo-nasal e tosse & 5 & 5 & - \\
\hline & Convulsão, ataxia, tosse e secreção óculo-nasal & 4 & 4 & - \\
\hline Total & & 87 & 41 & 46 \\
\hline
\end{tabular}

Os cães do grupo B apresentavam alterações neurológicas tais como ataxia, convulsão e mioclonia (Tab. 2), consideradas características da cinomose canina (Shell, 1990; Zubriggen et al., 1995; Greene, 1998). Nesse grupo, a RTPCR foi positiva em apenas $29,7 \%$ das amostras avaliadas. Outras doenças, infecciosas ou não, podem determinar alterações neurológicas semelhantes à cinomose. Nessas situações, o diagnóstico diferencial é fundamental para a escolha do tratamento adequado, bem como para a definição do prognóstico da doença, uma vez que, na forma nervosa da cinomose canina, o prognóstico é reservado sendo, em muitas situações, de acordo com a evolução clínica, indicada a eutanásia.

A diferença entre as freqüências de positividade para o CDV encontrada nos cães com sinais clínicos sistêmicos e neurológicos não foi significativa $\left(\mathrm{P}=0,0899\right.$ e $\left.\chi^{2}=2,88\right)$. Esse resultado demonstra que, na população estudada e com a abordagem utilizada, a probabilidade de um cão que apresentou sinais clínicos sistêmicos ou neurológicos estar com cinomose canina foi a mesma.
No grupo C, constituído por cães que apresentavam simultaneamente sinais clínicos sistêmicos e neurológicos, foi possível detectar o CDV em todas as nove amostras de urina analisadas (Tab. 2). Apesar de nenhum sinal clínico ser patognomônico da cinomose, a ocorrência simultânea de um grupo deles facilita o diagnóstico da doença (Appel e Summers, 1999). Gebara et al. (2004) também descreveram a detecção do RNA do CDV a partir de amostras de urina de cães com sinais clínicos sistêmicos e neurológicos simultaneamente. Comparando-se a diferença de freqüência de sinais clínicos entre os grupos $\mathrm{C}$ e $\mathrm{A}$, e os grupos $\mathrm{C}$ e $\mathrm{B}$, obteve-se nível de significância para ambas as associações $\left(\mathrm{P}=0,0198\right.$ e $\chi^{2}=5,43 ; \mathrm{P}=0,0006$ e $\chi^{2}=11,83$, respectivamente). Esse resultado demonstra que nas situações onde ocorrem simultaneamente sinais clínicos sistêmicos e neurológicos a probabilidade da realização do diagnóstico clínico é maior.

Shin et al. (1995) detectaram, por RT-PCR, o gene da nucleoproteína do CDV em 53,1\% das amostras $(n=32)$ de células mononucleadas provenientes de cães com sinais clínicos de cinomose. Apesar dessa freqüência de positividade ser bastante próxima à identificada 
no presente trabalho $(47,1 \%)$, esses autores utilizaram dois pares distintos de oligonucleotídeos iniciadores, o que torna a técnica mais laboriosa e de maior custo.

Frisk et al. (1999), ao utilizarem os mesmos oligonucleotídeos iniciadores empregados no presente trabalho, porém com estratégia de amplificação diferenciada, obtiveram a freqüência de $88 \%$ de animais positivos. Porém, deve-se ressaltar que nesse trabalho foram empregadas apenas amostras biológicas provenientes de cães com diagnóstico de cinomose confirmado por imunoistoquímica, o que justifica o maior percentual de positividade.

A leucocitose foi a alteração hematológica mais freqüente nos grupos de cães com sinais clínicos (grupos $\mathrm{A}, \mathrm{B}$ e $\mathrm{C}$ ). $\mathrm{O}$ número de leucócitos totais nos animais desses três grupos foi muito semelhante, independentemente do resultado da RT-PCR. Outras alterações como linfopenia, leucopenia e anemia foram encontradas em menor freqüência de ocorrência. Nos cães do grupo D (controle), dois animais apresentaram anemia e leucocitose, que retornaram a valores normais 15 dias após a primeira análise. Estes achados ratificam as observações de que apenas os dados hematológicos não são suficientes para a realização de diagnóstico diferencial, uma vez que eles podem ser influenciados por diversos aspectos tais como a estirpe viral infectante, a fase de multiplicação do vírus no momento da colheita do sangue e a presença ou não de infecções bacterianas secundárias (Axthelm e Krakowka, 1987; Greene, 1998). A freqüência das características hematológicas encontradas nos 107 cães incluídos neste estudo, distribuída de acordo com o resultado da RT-PCR, pode ser visualizada na Tab. 3 .

Tabela 3. Freqüência das características hematológicas encontradas em cães com diferentes formas clínicas sugestivas da infecção pelo vírus da cinomose canina, distribuída de acordo com o resultado da RT-PCR

\begin{tabular}{lccc} 
Característica & $\begin{array}{c}\text { Freqüência } \\
\text { hematológica }\end{array}$ & Amostra & \multicolumn{2}{c}{ RT-PCR } \\
\cline { 3 - 4 } & 58 & Positiva (\%) & Negativa (\%) \\
\hline Leucocitose & 16 & $7(43,7)$ & $30(51,7)$ \\
Leucopenia & 9 & $5(55,6)$ & $4(46,3)$ \\
Linfopenia & 12 & $5(41,7)$ & $7(58,3)$ \\
Anemia & 5 & $3(60,0)$ & $2(40,0)$ \\
Nenhuma alteração & &
\end{tabular}

No período de até 15 dias de avaliação da evolução clínica seis cães, pertencentes ao grupo A e que foram positivos na técnica da RT-PCR, evoluíram para a fase neurológica da doença, com sinais de mioclonia e, por solicitação dos proprietários, foram submetidos a eutanásia. Ainda nesse período, a taxa de mortalidade entre os cães com sinais clínicos (grupos A, B e C), porém negativos na RT-PCR, foi de $17,4 \%$ (8/46). Nos cães negativos do grupo A houve três óbitos: dois após gastroenterite hemorrágica e um que desenvolveu pneumonia grave. Nenhum dos cães negativos do grupo A apresentou alterações neurológicas. Entre os cães negativos do grupo B (26/37), quatro foram submetidos a eutanásia por desenvolverem alterações neurológicas incompatíveis com a vida e um animal veio a óbito por complicações bacterianas secundárias. A taxa de mortalidade de 58.5\% (24/41) observada nos cães positivos para o CDV foi significativamente maior $(\mathrm{P}=0,0002 \mathrm{e}$ $\chi^{2}=14,06$ ) do que a encontrada nos cães com resultado negativo na RT-PCR. Entretanto, devese ressaltar que não foram realizados testes em paralelo para a identificação de outros agentes infecciosos que podem ocasionar sinais clínicos semelhantes aos apresentados pelo cães incluídos neste estudo.

Todos os animais do grupo controle (D) foram também avaliados por até 15 dias após a colheita de material biológico (urina/sangue) e nenhum deles apresentou qualquer sinal clínico sistêmico e/ou neurológico durante esse período.

Exceto nas situações em que o animal apresenta sinais clássicos de mioclonia, com freqüência, o diagnóstico, tanto clínico quanto laboratorial, da cinomose canina é de difícil realização. Em vários casos o diagnóstico clínico é incerto (Shell, 1990) e alterações hematológicas, bioquímicas e mesmo exames realizados no líquor podem não ser conclusivos (Greene, 1998; Frisk et al., 1999; Moritiz et al., 2000). Nos casos de evolução subaguda ou crônica a pesquisa de corpúsculo de inclusão pode ser negativa (Appel e Summers, 1999) assim como também a imunofluorescência direta (Shin et al., 1995). Para o diagnóstico ante morten a microscopia eletrônica, apesar de se revelar como um método útil, é de uso limitado. O isolamento do vírus em cultivo celular não é uma metodologia freqüente de diagnóstico da cinomose canina, particularmente por ser um método laborioso, 
demorado e por apresentar bons resultados somente em cães na fase aguda da doença. O isolamento do CDV pode ainda apresentar como fator limitante a interferência de anticorpos que podem estar presentes no material biológico a ser analisado (Appel e Summers, 1999). A histopatologia, quando revela alterações histológicas clássicas, é um bom método diagnóstico. Porém, apresenta como desvantagem a confirmação do diagnóstico somente post mortem. Outro método de diagnóstico post mortem da infecção pelo CDV é a imunoistoquímica que apresenta melhores resultados somente nos casos de viremia, o que não acontece na forma crônica da infecção (Gathumbi, 1993; Moritz et al., 2000).

Métodos moleculares como a RT-PCR vêm sendo desenvolvidos com o objetivo de proporcionar o diagnóstico de forma rápida e, principalmente, para contornar os inconvenientes da não síntese de proteínas virais nas formas subaguda e crônica ou da presença de anticorpos, que podem interferir substancialmente na maioria dos métodos de diagnóstico ante mortem. A RT-PCR pode resultar positiva mesmo em situações em que o isolamento viral e a imunoistoquímica são negativos (Shin et al., 1995; Appel e Summers, 1999; Frisk et al., 1999). Apesar de sensível e específica, a RTPCR pode também não excluir a infecção. Nesse caso, os resultados podem sofrer interferência de vários fatores tais como: seleção da seqüência alvo de nucleotídeos a ser amplificada, método de extração do RNA a ser utilizado, padronização dos reagentes empregados na técnica, seleção do material biológico a ser utilizado para o diagnóstico, forma de conservação e tempo de estocagem, uma vez que trata-se de um vírus cujo genoma é constituído por RNA de fita simples, que pode facilmente sofrer degradação. Entretanto, essa técnica, após adequada padronização, pode revelar-se como uma das principais ferramentas para o diagnóstico etiológico ante mortem da infecção pelo CDV.

Considerando a inespecificidade dos sinais clínicos e das alterações hematológicas nas infecções pelo CDV, os resultados deste estudo ratificam a importância do desenvolvimento de métodos de diagnóstico etiológico para essa virose. A RT-PCR para a detecção do gene da nucleoproteína do CDV, utilizando a urina como amostra biológica, proporcionou o diagnóstico ante mortem da cinomose em cães com sinais clínicos sugestivos da infecção. O emprego de um método sensível de diagnóstico ante mortem do CDV permite que condutas adequadas de tratamento e profilaxia, tanto da cinomose canina quanto de outras enfermidades que apresentam sinais clínicos semelhantes, possam ser adotadas com antecipação e eficiência.

\section{REFERÊNCIAS BIBLIOGRÁFICAS}

APPEL, M.J.G.; SUMMERS B.A. Canine distemper: Current status. Disponível em:


mar. 2002.

APPEL, M.J.G.; SUMMERS B.A. Pathogenicity of morbilliviruses for terrestrial carnivores. Vet. Microbiol., v.44, p.187-191, 1995.

AXTHELM, M.K.; KRAKOWKA S. Canine distemper virus-induced trombocytopenia. Am. J. Vet. Res., v.48, p.1269-75, 1987.

BOOM, R.; SOL, C.J.A.; SALIMANS, M.M.M. et al. Rapid an simple method for purification of nucleic acids. J. Clin. Microbiol., v.28, p.495503, 1990.

CARLTON, W.W.; McGAVIN, M. Patologia veterinária especial. 2.ed. Porto Alegre: ArtMed, 1998. 672p.

DEAN, A.G.; DEAN, J.A.; COULOMBIER, D. et al. Epi Info versão 6.04. Disponível em: http://www.cdc.gov/epinfo./ei6faq.htm. 1997.

FELDMAN, B.V.; ZINKL, J.G.; JOIN, N.C. Schalm's veterinary hematology. 5.ed. Lippincott Williams \& Wilkins, 2000. 787p.

FRISK, A.L.; KONIG, M.; MORITZ, A. et al. Detection of canine distemper virus nucleoprotein RNA by reverse transcription-PCR using serum, whole blood, and cerebrospinhal fluid from dogs with distemper. J. Clin. Microbiol., v.37, p.3634-3643, 1999.

GATHUMBI, P.K. The retrospective use of a peroxidase technique for confirmation of suspected canine distemper in Kenya. Vet. Res. Comm., v.17, p.197-201, 1993.

GEBARA, C.M.S.: WOSIACKI, S.R.; NEGRÃO, F.J. et al. Lesões histológicas no sistema nervoso central de cães com encefalite e 
diagnóstico molecular da infecção pelo vírus da cinomose canina. Arq. Bras. Med. Vet. Zootec., v.56, p.168-174, 2004.

GREENE, G.E. Infectious diseases of the dog and the cat. Philadelphia: W.B. Saunders, 1998. $820 \mathrm{p}$.

JONES, C.T.; HUNT, D.H.; KING, N.W. Patologia veterinária. São Paulo: Manole, 2000. $1415 \mathrm{p}$.

MORITIZ, A.; FRISK, A.L.; BAUMAGRTNER, $\mathrm{W}$. The evaluation of diagnostic procedures for detection of canine distemper virus infection. Europ. J. Comp. Anim. Pract., v.10, p.37-45, 2000.

MOTOHASHI, T.; NAKAGAWA, H.; OKADA, T. Fluorescent antibody technique in diagnosis of canine distemper. Vet. Med. Small Anim. Clin., v.65, p.1057-1059, 1969.

RUDE, T.A. Canine distemper virus: infection and prevention. Can. Pract., v.14, p.16-24, 1987.

SAITO, T.B. Padronização da técnica da Reação em Cadeia pela Polimerase (RT-PCR) para o diagnóstico ante e post mortem do vírus da cinomose canina. 2001. 100f. Dissertação
(Mestrado) - Universidade Estadual de Londrina, Londrina, PR.

SHELl, L.G. Canine distemper. Comp. Small Anim., v.12, p.173-179, 1990.

SHIN, Y.; MORI, T.; OKITA, M. et al. Detection of canine distemper virus nucleocapsid protein gene in canine peripheal blood mononuclear cells by RT-PCR. J. Vet. Med. Sci., v.57, p.439-45, 1995.

TIPOLD, A. Diagnosis of inflamatory and infectious diseases of the central nervous system in dogs: a retrospective study. J. Vet. Int. Med., v.9, p.304-314, 1995.

VAN REGENMORTEL, M.H.V.; FAUQUET, C.M.; BISHOP, D.H.L. et al. Virus taxonomy: The classification and nomenclature of viruses. REPORT of the International Committee on Taxonomy of Viruses, 7. San Diego: Academic, 2000. 1167pp.

ZUBRIGGEN, A.; GRABER, H.U.; VANDELVEDE, M. Seletive spread and reduced virus release leads to canine distemper virus persistence in the nervous system. Vet. Microbiol., v.44, p.281-288, 1995. 